\title{
EL ESTANQUE DE MERCURIO DEL ALCÁZAR DE SEVILLA (1572-1577): UN BALANCE DE PÉRDIDAS
}

\section{THE MERCURY POND OF THE ALCÁZAR DE SEVILLA (1572-1577): A BALANCE OF LOSSES}

\author{
Alfonso Pleguezuelo \\ Universidad de Sevilla. España \\ ORCID: 0000-0002-8235-3082 \\ aplegue@us.es
}

\begin{abstract}
El propósito principal de este ensayo es hacer una lectura crítica de la documentación publicada sobre la reforma renacentista de este fragmento de los jardines del Alcázar. Se hace aquí una detallada descripción del proceso de obras y esta narración permite descubrir los cambios operados con el paso del tiempo y el progresivo deterioro de este espacio. El conjunto ha ido perdiendo elementos formales, rasgos cromáticos y planteamientos hidráulicos que tuvieron en el pasado una belleza y una sofisticación que podría ser recuperada en gran parte con una restauración que pudiera ser planteada al mismo nivel del proyecto inicial.

Palabras clave: Renacimiento; Sevilla; Alcázar; Estanque de Mercurio; jardines.
\end{abstract}

The main purpose of this essay is to make a critical reading of the published documentation on the Renaissance reform of this fragment of the gardens of the Alcázar. A detailed description of the process of works is made here and this narration allows us to discover the changes that took place with the passage of time and the progressive deterioration of this space. The ensemble has been losing formal elements, chromatic features and hydraulic approaches that had in the past a sophistication that could be recovered largely with a restoration that could be raised to the same level of the initial project.

Keywords: Renaissance; Seville; Alcázar; Mercury Pond; gardens.

Clarificar la historia material de este reducido pero esencial espacio de los jardines del Alcázar y hacer memoria de algunos rasgos y elementos que tuvo en su origen y que hoy ha perdido son los sencillos objetivos que me han impulsado a recopilar y reordenar numerosos datos que ya fueron publicados hace más de un siglo por Gestoso y completados más tarde por Ana Marín ${ }^{1}$. La valiosa

${ }^{1}$ GESTOSO Y PÉREZ, José: Sevilla monumental y artística. T. I. Sevilla, 1889; y MARÍN FIDALGO, Ana: El Alcázar de Sevilla bajo los Austrias. 2 vols. Sevilla, 1990. 
información que los dos autores han publicado sobre el Alcázar y sus jardines renacentistas a partir de la consulta de su archivo fue ordenada en ambas obras con un criterio cronológico o en función de los maestros de obra que las dirigieron, lo que les obligaba a exponer de forma fragmentaria y dispersa la información desde un punto de vista topográfico, siendo este último, sin embargo, el más útil cuando se va a emprender una intervención de conservación o de restauración en un espacio concreto del conjunto. Con independencia de tal ventaja que se ofrece a restauradores y arquitectos, también se constata como experiencia habitual del historiador que, al ordenar y analizar críticamente todos los datos disponibles sobre un ámbito, afloran facetas y problemáticas que de otra forma quedan desapercibidas, razón por la cual este nuevo tratamiento de la información que aquí hacemos podría tal vez justificar esta aparente reiteración en la que los trabajos anteriores, especialmente el colosal esfuerzo documental de Gestoso, serán repetidamente citados. En 1988 la misma Ana Marín realizó una primera síntesis sobre la historia constructiva de la totalidad de los jardines renacentistas del Alcázar, un trabajo muy útil aunque hemos considerado que una visión monográfica sobre uno de aquellos espacios podría ser buena ocasión para replantear algunos detalles y cuestiones de importancia para el planteamiento de una, ya urgente, actuación restauradora que desde aquí pretendemos estimular ${ }^{2}$.

El estanque dedicado a Mercurio fue en 1572 el primero de los ámbitos exteriores del Real Alcázar, entre los adosados a su fachada sur, que inicia obras de remodelación renacentista aunque esta operación parcial formaba parte de un programa más ambicioso que tuvo la finalidad de dar una nueva apariencia a los espacios comprendidos entre los palacios gótico y mudéjar y la muralla baja que separaba a ambos de la Huerta de la Alcoba. El inicio de las obras en el estanque fue simultáneo a las que se emprenden en el Jardín llamado más tarde de la Danza, el del Laberinto, el de la Galera y el de las Flores. Parece que en su exterior solo existía entonces el llamado Jardín del Príncipe, adosado a la fachada oeste, aunque en la zona oriental se mencionan también el jardín del Conde y el de la Alcobilla ${ }^{3}$. Desde época del emperador Carlos también existió en las huertas, a un nivel más bajo que los palacios, el Cenador de la Alcoba, que no era un jardín stricto sensu, sino un pabellón arquitectónico en medio de una densa huerta de cítricos y muy cercano al Estanque del León antes de la reforma que a mediados del siglo XVII añadió el cenador que hoy le sirve de fondo.

${ }^{2}$ MARÍN FIDALGO, Ana: "Los jardines del Alcazar sevillano durante los siglos XVI y XVII. Intervención y ordenaciones del conjunto en el Quinientos", Cuadernos de la Alhambra, 24, 1988, pp. 109-141. Las obras del estanque se describen de forma resumida en las páginas 129 y 130.

${ }_{3}$ Para un panorama general de la evolución de los jardines en el siglo XVI véase también BONET CORREA, Antonio: "El Renacimiento y el Barroco en los jardines barrocos españoles”, Cuadernos de la Alhambra, 4, 1968, pp. 2-26. 
Todo parece indicar que el espacio del gran estanque que luego sería de Mercurio, por el hecho físico de tener sus paseaderos al mismo nivel que los pavimentos del propio palacio gótico, era el primero del flanco meridional al que accedía desde sus salones todo aquel que deseara salir al exterior y pasear por las entonces huertas del Alcázar, situadas todas ellas a un nivel más bajo que el conjunto palatino medieval. Por ello era el primero de esta zona que precisaba ser transformado como forzoso tránsito. En consonancia con la nueva cultura simbólica del humanismo que afectó al concepto de jardín, la primitiva función agrícola del estanque como depósito de agua de riego sería transformada en un nuevo espacio mitológico de resonancias clásicas, aspecto simbólico que no abordaremos aquí por haber sido analizado ya con detalle y perspicacia por Vicente Lleó, brillante colega y amigo a quien va dedicado este modesto artículo y la revista en que se incluye ${ }^{4}$.

Las obras de transformación comienzan muy poco después de la estancia en Sevilla de Felipe II en 1570 y no sabemos si, tal vez, como efecto de alguna disposición que dejó encomendada el monarca o su arquitecto de confianza Luis de Vega. Lo que sí es evidente es que el proyecto en que se inscribe la obra del estanque no se limitaría a este único espacio sino que sería fruto de un programa de intervenciones más global que implicaría al propio Palacio Gótico y a los jardines que quedarían alineados, a partir del estanque, en la fachada meridional.

El texto de un pago librado en 1572 ha tentado a más de un autor a pensar que este espacio era llamado Jardín del Chorrón, aunque quedan testimonios documentales que dejan claro que el conocido entonces con tal nombre -y hoy como Jardín del Cidral- estaba a su mismo nivel pero a sus espaldas, situado entre la esquina sureste del Palacio Gótico, el Cuarto del Cidral y la muralla que integraba la Torre del Agua ${ }^{5}$. El que desde ahora sería el Estanque de Mercurio era

${ }^{4}$ LLEÓ CAÑAL, Vicente: Nueva Roma. Mitología y Humanismo en el Renacimiento Sevillano. Sevilla, 2001, pp. 122-123.

${ }^{5}$ Entre las varias noticias documentales que dejan clara esta identificación podemos mencionar uno de los pagos hechos al herrero Juan Barba cuando entrega "dos rejas de hierro que se pusieron en la «sala grande» (Sala de las Bóvedas) en dos ventanas que salían sobre el «Jardín del Chorrón»”. MARÍN, Ana: El Alcázar de Sevilla..., op. cit., vol. 2, p. 253 y nota 143. Las enormes rejas, que permiten iluminar esa sala, hoy llamada de la Cantarera, aún están in situ. En este mismo espacio sigue estando la llamada Torre del Agua por ser el punto en que estaba situada el arca de agua que llegaba al Alcázar. No sería extraño que la propia entrada del agua en la caja se hiciera con algún desnivel y que la corriente formara un chorro de grosor y flujo considerable. No podemos descartar que el chorro pudiera verter sobre la alberca cuando estos dos espacios estaban unificados antes de ser segregados como hoy se ven desde 1573. Lo que es más improbable es que lo hiciera desde la altura que hoy lo hace. 


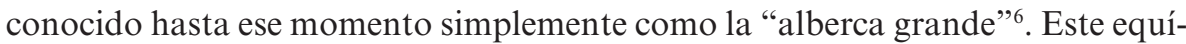
voco es el que condujo a Joaquín Romero Murube, conservador del monumento entre 1934 y 1969, a decidir la instalación del enorme chorro de agua que desde entonces cae sobre el estanque que ahora nos interesa, desde un caño que asoma por el mirador situado encima de la entrada a este ámbito, instalación que, con independencia del posible atractivo que posea para el turismo de masas, en absoluto se corresponde con la delicadeza del tratamiento que el agua tuvo primitivamente en este espacio, como se comprobará a continuación y, lo que es peor, se ha convertido con los años en el agente de deterioro más agresivo de cuantos actúan de forma continua sobre este emblemático lugar.

Será precisamente en este ciclo de obras que se inicia hacia 1572 cuando el Jardín del Chorrón y el estanque quedan divididos por la crujía que ahora los separa, compuesta por el profundo arco de paso entre ambos, el cenador situado entre el arco y la muralla y el mirador y azotea -llamado entonces "terrado"- situados sobre ambos elementos ${ }^{7}$. Ello se deduce de varios pagos, entre otros, uno de junio de 1573, librado a los albañiles que trabajan haciendo "una zanja para alzar una pared entre una torre de junto al estanque (la Torre del Agua) y el terrado del Quarto Real (azotea del Palacio Gótico)"8 (Figuras 1-2).

Otros pagos que se hacen muy poco después se refieren a la amplia galería de tres arcos, abierta al Jardín de la Danza, que comunica la Sala de las Bóvedas y el Jardín del Chorrón, paso que ya existía desde antes pero que ahora se amplía trasladando de lugar la antigua arcada y enrasándola con la línea de fachada del palacio $^{9}$ (Figura 3).

Sobre el espacio que hoy ocupa el estanque no han quedado noticias documentales de las posibles obras de albañilería previas a la fabricación de sus bancos, sus antepechos y sus revestimientos; tal vez porque no se modificarían los ya preexistentes. El estanque existía, al parecer, desde época islámica y sus paredes

${ }^{6}$ El nombre le venía por comparación con otros estanques menores que también servían para regar las huertas. Entre ellos destacaban uno al pie del Jardín del Príncipe, hoy desaparecido, y otro, el Estanque del León, situado junto al cenador de ese nombre.

${ }^{7}$ La importancia de este nivel superior fue uno de los móviles que actuaron en la construcción de este elemento separador de ambos espacios ya que se pretendía establecer un paso directo entre el Cuarto Real alto y la galería que recorría la muralla que más tarde sería revestida con un orden rústico. Parte de esta azotea que hacía de tránsito se aprovechó a inicios del siglo XVII para construir el mirador que hoy vemos abierto sobre el estanque y que sustituye al que fue construido poco después de 1573 .

${ }^{8}$ GESTOSO Y PÉREZ, José: Sevilla monumental..., op. cit., p. 552.

9 Se paga entonces a los obreros por una pared "que se hace en los jardines para pasaje del quarto real alto para el corredor de sobre el estanque", y otro pago se refiere igualmente a "la pared que se haze en el jardín que está junto al estanque para pasar del Cuarto Real al corredor sobre el estanque y a los jardines". GESTOSO Y PÉREZ, José: Sevilla monumental..., op. cit., pp. 552-553. 
debían ser muy gruesas para soportar las presiones del considerable volumen de agua que contenían aunque no sabemos sin antes practicar un registro, si su grosor fue aumentado hasta la amplitud que hoy tienen los andenes que lo rodean. Tampoco sabemos cuál sería el estado y aspecto de la muralla a la que el estanque se adosa por su lado oriental puesto que lo que hoy vemos es un orden de aparejo rústico, sobrepuesto a la misma, que sería construido a inicios del siglo XVII. Apenas tenemos indicios para pensar que aquel muro militar tuviera entonces una especial significación estética.

Lo cierto es que el elevado número de noticias documentales que Gestoso reúne comienza con labores de revestimiento de elementos que ya se mencionan como construidos. En los meses de marzo, abril, mayo y junio de 1572, los albañiles del Alcázar están asentando alizares en los bancos y los pretiles del citado muro del lado sur y en febrero del año siguiente aún continúan estas labores ${ }^{10}$. Poco después empiezan a asentarse los mismos materiales en los pavimentos de los andenes del propio estanque y también se siguen revistiendo bancos, respaldos y antepechos, llamados en los documentos "poyos" y "acodaderos".

Dado que estos andenes eran simples lugares de paseo y tránsito, el único espacio habitable de este nuevo ámbito en planta baja era un cenador que en este momento se construye junto a él, abierto al norte en su fondo, es decir, al viejo Jardín del Chorrón, con dos grandes ventanas con rejas de forja, y al sur mediante un doble arco, apoyado en una columna y capitel de mármol. Un pago de septiembre de 1574 así lo consigna ${ }^{11}$. Por tanto, durante esta fase que transcurre entre 1572 y 1574 se van asentando los ladrillos, azulejos, alizares y olambrillas en todos los revestimientos horizontales $-\mathrm{y}$ tal vez verticales que más tarde desaparecieron- que rodean el viejo estanque.

El pavimento que hoy vemos es el original a excepción de algunos arreglos parciales y de las numerosas olambrillas sustituidas. Sigue un esquema que fue muy frecuente en el siglo XVI, que simula una trama textil o de cestería. Se forma con los alizares verdes, usados en los ángulos batientes, las olambrillas de arista decoradas con los cinco colores habituales de los vidriados mudéjares de este momento y los ladrillos raspados rectangulares, de pasta cerámica de dos colores, rosáceo y pajizo, colocados de forma alterna como aún puede comprobarse

${ }^{10}$ GESTOSO Y PÉREZ, José: Sevilla monumental..., op. cit., pp. 545, 546, 547 y 551. Es preciso aclarar que el pretil y bancos que hoy existen no son los originales sino otros hechos posteriormente. De las diferencias entre los primitivos y los actuales parecen quedar leves indicios en la geometría de los pavimentos, solo en parte originales, del andén antepuesto a los mismos.

11 "asentando olambres en el cenador junto al estanque". GESTOSO Y PÉREZ, José: Sevilla monumental..., op. cit., p. 555. 
si analizamos con cierto detenimiento las partes más primitivas ${ }^{12}$. Es preciso recordar que son muy escasos los pavimentos del siglo XVI que se conservan y ello convierte este en un valioso ejemplo que lo hace digno de ser conservado (Figura 4). Con independencia de este valor patrimonial, tiene otro documental pues precisamente el esquema geométrico original de su colocación es el que delata una organización diferente a la actual en los muros colindantes con el Jardín de las Damas y con el Jardín de la Danza, incongruencias lógicas ya que sabemos que tanto el antepecho y bancos que limita con el primero como la escalera que hace de tránsito al segundo, fueron modificados en época posterior respecto de las obras originales del siglo XVI.

No se tienen noticias de los contratos de suministros que pudieran haberse firmado en relación a los materiales cerámicos, pero sí ha quedado constancia documental de los maestros azulejeros que envían sus productos a la obra. Uno de ellos es Roque Núñez, ya que a fines de junio y principios de julio de 1573 se pagan a Melchor de los Reyes, criado del ceramista, cerca de 1.000 olambrillas y también se abona a Antón Sánchez el transporte del material desde Triana hasta los Alcázares ${ }^{13}$. A la semana siguiente se hace el pago al mismo Melchor de los Reyes, esta vez mencionado como criado de otro importante ollero, Roque Hernández ${ }^{14}$. Durante las semanas siguientes continúa el pago de olambres a ambos alfareros ${ }^{15}$. Es posible que Roque Núñez y Roque Hernández, fabricantes de toda la cerámica vidriada aplicada en este ámbito, no sólo compartieran criado sino quizá también obrador. Durante todos estos meses en que llegan los materiales cerámicos al Alcázar, se va pagando a los obreros que van asentando todo este material en los bancos, respaldos, poyetes y pavimentos de los andenes y del cenador, tareas que se terminan en agosto de 1573.

${ }^{12}$ Lamentablemente, muchos de los arreglos que se hicieron en el pasado ignoraron esta sutil alternancia de colores aunque precisamente esas torpes actuaciones nos sirven hoy para diferenciar las partes originales de las partes renovadas.

13 "1463 reales por 975 olambres que dio para los andenes". GESTOSO Y PÉREZ, José: Sevilla monumental..., op. cit., p. 553.

14 "4 ducados que son por 1000 olambres de azulejos que dio para las obras". GESTOSO Y PÉREZ, José: Sevilla monumental..., op. cit., pp. 553-554.

${ }^{15} \mathrm{La}$ siguiente semana se pagan sumas parecidas por 840 olambres. GESTOSO Y PÉREZ, José: Sevilla monumental..., op. cit., p. 554. De nuevo, en agosto se abonan, esta vez a Roque Núñez, ochocientas "tablas de azulejos... para los olambres de los andenes del estanque”. GESTOSO Y PÉREZ, José: Sevilla monumental..., op. cit., p. 555. No sabemos a qué tipo de piezas se llamaba "tablas de azulejo" en este momento aunque es posible que se tratara de verduguillos rectangulares. Finalmente, en agosto de este mismo año se pagan a un criado negro de Roque Hernández llamado Antonio, "200 verduguillos de azulejos a un maravedí cada uno”. GESTOSO Y PÉREZ, José: Sevilla monumental..., op. cit., p. 556. 
Es escaso lo que lamentablemente ha quedado de todo este material cerámico pero parte de las olambrillas y casi todos los alizares verdes aún están in situ, especialmente las piezas arrimadas al muro de la Galería de Grutesco y las situadas justamente bajo la balaustrada del estanque donde reciben menos daños. El continuo desgaste de estas olambrillas ha provocado renovaciones periódicas de forma que hallamos entre ellas, además de las originales, otras de los siglos XVII, XVIII, XIX y XX. Casi podríamos decir que la historia de las olambrillas sevillanas está resumida en esta reducida superficie. Igualmente parecen ser parte del conjunto primitivo -aunque la documentación no menciona la palabra "azulejo" - un cierto número de ellos, datables en este mismo momento, que revisten un canal de agua, hoy en desuso, que recorre, atravesándola, la parte baja del muro de la Galería de Grutescos. El hecho de haber quedado oculto parte del pavimento del andén de este lado, nos indica que este canal fue construido al tiempo que se forma el mismo frontis de orden rústico proyectado por Vermondo Resta a principios del siglo XVII, aunque produce la impresión que los azulejos que revisten interiormente esta atarjea, datables en el siglo XVI, pudieron ser aprovechados de un zócalo que originalmente pudo revestir la parte baja de este mismo muro antes de ser ocultado por la Galería de Grutescos. Todos estos azulejos y olambrillas fueron ornamentados con el procedimiento de la arista y con el repertorio habitual que se empleaba desde principios del siglo XVI aunque aumentado en la proporción de motivos figurativos sobre los geométricos mudéjares, antes mayoritarios. Ya por estos años era posible decorar azulejos pintados a pincel, siguiendo el método de origen italiano que emplearía tres años después el yerno de Roque Hernández, Cristóbal de Augusta, para ejecutar los zócalos del palacio gótico. Precisamente había sido Roque Hernández el ceramista de Triana que había firmado en 1561 un contrato de compañía con otro colega venido de Amberes, Frans Andríes -en Sevilla, Francisco Andrea-, para que este le enseñara a practicar la técnica que ya había sido implantada en Sevilla setenta años antes por Niculoso Francisco Pisano pero que muy probablemente se había perdido con su fallecimiento y el de su hijo ${ }^{16}$.

En resumen, los azulejos, olambrillas y alizares originales que aquí se conservan son atribuibles indistintamente a Roque Núñez y Roque Hernández y constituyen, además, las únicas obras identificadas de estos dos ceramistas que hasta ahora sólo conocíamos por documentos.

Terminada esta fase de revestimientos cerámicos, se procedió a encargar los trabajos de forja, cantería, bronce, dorado y pintura. El estanque quedaría protegido por unas barandas y el herrero encargado de forjarlas fue Juan Fernández, quien empezó a entregar los elementos fabricados a mediados de julio de $1575^{17}$.

${ }^{16}$ Este importante documento fue publicado por GESTOSO Y PÉREZ, José: Historia de los barros vidriados sevillanos. Sevilla, 1903, pp. 223-ss.

${ }^{17}$ GESTOSO Y PÉREZ, José: Sevilla monumental..., op. cit., p. 567. 
Cada paño de baranda se componía de veinticinco balaustres, remachados en las pletinas baja y alta -llamadas "mesas" en la época-, que armaban la estructura de cada tramo. Los paños de baranda de hierro quedarían sujetos a veintidós pedestales de mármol que encargan a Pedro de Arrieta, quien los entregó a fines de noviembre de $1575^{18}$. Después de que Arrieta hiciera los esbeltos pedestales de la balaustrada con diseños que le suministró Diego de Pesquera, como se verá más adelante, también fue encargado al cantero Gerónimo Luis un pedestal más, del mismo material, para ubicarlo aisladamente en el centro del estanque, elemento sobre el que sería colocada la urna rematada en la figura de Mercurio y otras más de menor tamaño ${ }^{19}$. En 1900, fueron sustituidos cuatro de estos pedestales de mármol por estar quebrados ${ }^{20}$.

La faceta figurativa de este proyecto exigió la intervención de un escultor, un fundidor y un dorador, como era habitual cuando se trataba de obras de bronce. Por una parte, el Alcázar acudió a un artista de gran prestigio para hacer los diseños y crear los modelos tridimensionales de las esculturas y los relieves del conjunto, el antes citado Diego de Pesquera, escultor que en ese momento trabajaba para la cercana catedral ${ }^{21}$. Su tarea se prolongó dos años entre el primer pago librado en julio del 1575 y el último, en agosto de 1577. Comenzó Pesquera por suministrar los modelos de los dos elementos que habían de rematar los pedestales de la balaustrada. Uno de ellos representa un león heráldico que sostiene el escudo de castillos y leones. El otro modelo muestra una esfera rematada en pirámide, decorada con cuatro rostros de leones y apoyada en cuatro delfines que se transforman en hojas de acanto. Los leones serían ejecutados al año siguiente según leemos en la breve inscripción que muestran sus peanas: "ANNO 1576"22 (Figuras 5-6).

18 "a pedro de arrieta, marmolero, 44 reales por hazer veinte y dos pedestales questan de mármol alrededor del estanque en que están puestas las varandas de hierro veinte y dos encaxes para poner los remates que se pondrán en ellos en cada uno". GESTOSO Y PÉREZ, José: Sevilla monumental..., op. cit., p. 569. Por los tiempos verbales empleados en la redacción del pago, se percibe que en ese momento ya estaban colocadas las barandas y los pedestales aunque no así los remates de bronce de estos últimos.

${ }^{19}$ En julio de este mismo año de 1577 se pagan "95 reales por un piedestal que labró y horadó para poner en medio del estanque sobre el qual se forma la burnia y la figura de metal que están acabando". GESTOSO Y PÉREZ, José: Sevilla monumental..., op. cit., p. 590. Poco después debe instalarse con la ayuda de un andamiaje que fabrican los carpinteros el 13 de agosto 1577 "para poner el pedestal sobre el que se puso la fuente". GESTOSO Y PÉREZ, José: Sevilla monumental..., op. cit., p. 590.

${ }^{20}$ BAENA SÁNCHEZ, María Reyes: Los jardines del Alcázar de Sevilla entre los siglos XVIII y XX. Sevilla, 2003, p. 125.

${ }^{21}$ Sobre este escultor puede ser consultada la obra de HERNÁNDEZ DÍAZ, José: Imaginería Hispalense del Bajo Renacimiento. Sevilla, 1951, pp. 43-47.

${ }^{22}$ En la semana que comienza el 18 de julio de 1575 se le pagan "sesenta y seis Reales por dos modelos que hyzo el uno es un león con un escudo y el otro un [sic] pirámide que 
Al mismo tiempo que se concede al fundidor el permiso de compra de materiales, en diciembre de 1576, se paga también a Pesquera por los modelos de las piezas principales del grupo central del estanque pues se menciona la "burnia, la figura y ciertos remates para poner en el estanque"23 (Figura 7). El 8 de abril de 1577, es decir, cinco meses más tarde, se le pagan los 20 ducados que faltaban para completar los 70 en que se habían concertado todos los modelos que debía entregar $^{24}$. Finalmente, en agosto de 1577 se le hace el libramiento de un nuevo pago, de tenor algo confuso, que parece referirse a los modelos de dos figuras infantiles, al caduceo de Mercurio, al ¿almete? de la figura, a las pequeñas tarjas que decoran la urna, a un dibujo de los pedestales que debió suministrar al marmolista y a cuatro bocas de leones ${ }^{25}$ (Figura 8).

Ignoro qué es el almete de la figura - ¿tal vez el alma o eje interior que la sostiene?-, y tampoco adivino a qué se refieren las cuatro bocas de leones pues se observan cuatro pequeños rostros de estos felinos, colocados como ornamentos en el cilindro que sirve de base a la figura de Mercurio, aunque no parecen tener las bocas abiertas. Por otro lado, en las paredes externas de la gran taza de la fuente se observan ocho torsos de seres faunescos de cuyas bocas salen caños de agua, en la actualidad inutilizados y sustituidos por otros ocho caños, de mayor tamaño, ubicados entre estos personajes. Tal vez el administrador se refería a estos cuatro rostros aunque los confundiera con leones por los rasgos animalescos propios de los faunos ${ }^{26}$.

son para poner encima de los pedestriles del estanque". GESTOSO Y PÉREZ, José: Sevilla monumental..., op. cit., p. 567.

23 "a diego de pesquera, escultor, cinquenta ducados... a buena cuenta para hazer los modelos de las piezas arriba dichas para el dicho estanque”. GESTOSO Y PÉREZ, José: Sevilla monumental..., op. cit., p. 578.

24 "a diego de pesquera escultor 20 ducados en rreales son para cumplimiento y paga de los 70 ducados sobre 50 ducados que se le dieron en la hijuela del lunes que fue postrero del mes de diciembre del passado año de 1576 los quales los 70 ducados se le dan por un modelo que hizo para una burnia de frislera [?] que se hizo para poner en el estanque destos alcáçares y por otro modelo que hizo para una figura para poner sobre la dicha burnia y por reparar las dichas figuras". GESTOSO Y PÉREZ, José: Sevilla monumental..., op. cit., p. 584. Por el texto, redactado en tiempo pasado, se entiende que la obra ya está realizada.

25 "a diego de pesquera escultor 150 rs que son para dar modelos que hizo para dos niños y para el caduceo de la figura y por el modelo del almete [?] de la dha figura y por el modelo de las tarjuelas compartimentos con el dibujo de los rremates y pedestal de abajo de la burnia y mas cuatro bocas de leones todo lo qual conserto el señor alcaide con el dicho diego de pesquera en el dicho precio". GESTOSO Y PÉREZ, José: Sevilla monumental..., op. cit., p. 592.

${ }^{26}$ Imagino que la operación en que los caños originales fueron suplantados se debería a la mayor facilidad que planteaba el sustituirlos y no el limpiar sus conductos, tal vez 
De la ejecución en bronce de todos estos modelos se encargaría el mejor fundidor que había en la ciudad, Bartolomé Morel, que ya había realizado trabajos anteriores de mucha mayor complejidad, sobre todo, la enorme figura del Giraldillo para la torre de la catedral. En la semana que comienza en diciembre de 1576 se le abona el dinero para la compra de materiales ${ }^{27}$. Adquiere Morel, en efecto, todo el necesario como queda reflejado en dos pagos que se le hacen por su importe en agosto de $1577^{28}$, mes y año en que se le libra el segundo pago en el que también se incluyó la puesta en obra de todos los elementos ${ }^{29}$. La colocación de todos los remates se llevó a cabo en ese mismo momento, dado que en agosto de 1577 se paga este trabajo al marmolista ${ }^{30}$.

Resulta de enorme interés comprobar que todas estas figuras de bronce no quedarían en el color natural del metal sino que, siguiendo la mejor tradición clásica, revitalizada en el Renacimiento, serían doradas a fuego, operación que llevó a cabo Carlos de la Cruz según sabemos por pagos que se libran a su favor en diciembre de 1576 y en agosto de $1577^{31}$.

obstruidos. En cualquier caso, se trata de una modificación poco refinada que sería conveniente anular rehabilitando, si fuera posible, el sistema original.

27 "a bartolome morel, artillero, dozientos y setenta ducados los quales se le dan... para comprar cobre para hazer una burnia y una figura y ciertos remates para poner en el estanque destos alcáçares". GESTOSO Y PÉREZ, José: Sevilla monumental..., op. cit., p. 577.

28 "a bartolome morel 200 rs los quales se le dan sobre 270 ducados que tiene recibidos para en quenta de los maravedises que se le darán por hazer una burnia y fuente y una figura y unos niños para el estanque destos alcáçares rreales y unas piramides y unos leonsillos para poner en los pedestales questan alrrededor del estanque dieronseles los dichos 270 ducados en la hijuela del lunes postrero de diciembre de 1576”. GESTOSO Y PÉREZ, José: Sevilla monumental..., op. cit., p. 591.

29 "a Bartolomé morel 133,553 mrs que se le dan y pagan en esta manera los 72,285 mrs son por 51 arrovas y diez libras de bronce que pesaron neto una burnia, y una figura y cuatro niños y 18 piramides y cuatro leones con sus escudos y armas reales y otros aderezos que hizo y fundio para poner sobre la fuente y pedestales que están al derredor del estanque destos alcaçares los quales se le pagaron a rraçon de 15 ducados el quintal de dho bronce y los 168,300 mrs se le dan y pagan por la hechura y fundición de todas las dichas piesas asi de basiado como del repasado dellas fasta ponellas a punto de se poder dorar y otros 22 rs se le dan por sierto plomo y carbón y jornal de dos oficiales que se ocuparon dos días en ajustar y asentar todo lo dho y enplomarlo y aderesarlo que todo monta 241,333 mrs”. GESTOSO Y PÉREZ, José: Sevilla monumental..., op. cit., pp. 591-592.

30 "a gerónimo luis 90 reales por unas rregolas que hizo en los pedestales del estanque para poner 18 pirámides y cuatro leonsillos por rremates en 20 pedestales que son y otros rreparos que hizo para poner la fuente". GESTOSO Y PÉREZ, José: Sevilla monumental..., op. cit., pp. 590-591.

31 Diciembre de 1676: "a carlos de la cruz, dorador, treinta ducados, los quales se le dan... para dorar todas las piezas arriba dichas para el dicho estanque”. GESTOSO Y 
Pero el conjunto central del estanque no se limitaba, como lo vemos hoy, a las esculturas de bronce dorado sino que tuvo, además, cuatro esculturas de mármol que inicialmente dimos por desaparecidas aunque en una última revisión de los jardines hemos creído identificar alguna de ellas. Su existencia se deduce por algún indicio material y, sobre todo, por documentos que indirectamente tratan de ellas. Según Marín, ya existían colocadas en el centro de la alberca en 1573 cuando se han iniciado las obras y es posible que así fuera ${ }^{32}$. Lo cierto es que a fines de 1575, esto es, antes de terminarse los primeros bronces, ya estaban ejecutadas aunque ignoramos desde cuándo.

Lo que es seguro es que si acaso estuvieron colocadas antes de la reforma en el centro de la alberca, como sostiene Marín, serían solo elementos ornamentales pero no surtidores de agua. Este extremo viene indirectamente documentado por los pagos que hacen al marmolista para que convierta tales esculturas en surtidores de los que pudieran brotar finos chorros de agua que vertieran en el estanque. Su misión consistía en horadarlas interiormente y practicarles orificios para colocarles en los pezones los correspondientes caños de bronce. El documento del pago al marmolista Pedro de Arrieta no puede ser más explícito sobre la misión por la que se le abona su trabajo a mediados de noviembre de 1575: "cient reales por horadar un pedestal de mármol para la fuente que está en medio del estanque destos dichos alcázares y por horadar ocho agujeros en ocho tetas de cuatro figuras de mujeres que se forman encima del dicho pedestal para poner en cada un agujero de cada teta un cañito de metal por donde salga el agua y caiga en dicho estanque" 33 . Los pagos al latonero que fabricó los ocho caños que habrían de ser colocados en los pezones de las ninfas quedaron también registrados en el $\operatorname{archivo}^{34}$.

Estas figuras resultan de lo más congruentes con el gusto del momento y, de hecho, eran numerosos los ejemplos que podrían haberlas inspirado ya que estuvieron presentes no solo en jardines manieristas y en fuentes públicas italianas sino también en algunos jardines sevillanos del renacimiento temprano. En

PÉREZ, José: Sevilla monumental..., op. cit., p. 578. Agosto de 1577: “a carlos de la cruz dorador 190, $740 \mathrm{mrs}$ a cumplimiento de paga de 201,960 mrs que montaron las piesas que doró que son todas las arriba dhas". GESTOSO Y PÉREZ, José: Sevilla monumental..., op. cit., p. 592.

32 MARÍN, Ana: Los jardines del Alcázar..., op. cit., pp. 129 y 139.

${ }^{33}$ GESTOSO Y PÉREZ, José: Sevilla monumental..., op. cit., p. 568.

${ }_{34}$ Noviembre de 1575: "a francisco ximenez, latonero, cinquenta e dos rreales por ocho caños de laton torneados que dio para las figuras de la fuente de en medio del estanque, anse de poner en las tetas de las dichas figuras". GESTOSO Y PÉREZ, José: Sevilla monumental..., op. cit., p. 568. Febrero de 1576: "a francisco ximenez, latonero, 7 rs y medio por un cañito de latón que dio para poner en una de las figuras que están en la fuente que corre en medio del estanque”. GESTOSO Y PÉREZ, José: Sevilla monumental..., op. cit., p. 571. 
el apeo que se hace en 1543 de la Casa de Jerónimo Pinelo, se menciona en su pequeña huerta trasera otra escultura femenina de cuyos pechos también brotaban chorros de agua ${ }^{35}$. También resulta igualmente previsible que figuras tan profanas se convirtieran en blanco de las críticas de algunos moralistas que tal vez terminaran por lograr que fuesen eliminadas de aquel lugar, donde serían muy visibles, ya que este supuesto palacio privado del rey fue siempre relativamente público, especialmente a partir del siglo XVIII. Durante mucho tiempo nada sabíamos de estas cuatro figuras documentadas que dábamos por desaparecidas pero recientemente creo haber identificado una de ellas, ya muy degradada y reubicada en el contiguo Jardín de las Damas. Suponemos que fueron reubicadas con motivo de las obras de reforma que se hacen en este jardín cuando los antiguos muros que lo separaban de la Huerta de la Alcoba fueron demolidos y sustituidos por una de mayor transparencia lograda con rejas de hierro forjado y perforando las antiguas hornacinas, en cuyos huecos colocaron las damas que antes acompañaban a Mercurio (Figura 9). Contemplada de cerca se observan dos aspectos de cierto interés. Por un lado, su discreta calidad, lo que hace pensar que no debieron ser talladas por Pesquera, lo que parece confirmar la noticia dada por Marín relativa a su preexistencia. Por otro, se percibe que, aunque los dos pezones están perforados, el pecho izquierdo está descubierto pero no así el derecho, que está cubierto por la fina túnica que viste la figura. Si realmente esta figura fuese una de las cuatro en cuestión, fueron, en efecto, reutilizadas en la fuente de Mercurio y ello explicaría porqué no aparecen los pagos de su ejecución entre los demás.

Si sumamos los ocho caños que manaban en las cuatro figuras en la parte superior de la urna y los ocho que brotaban de las bocas de los ocho faunos de la parte baja, compondrían un juego de agua de diez y seis chorros radiales, congruentes con un esquema planimétrico tan centralizado como el de este estanque, es decir, un juego de aguas sencillo en su esquema pero mucho más complejo que el actual.

A esto habríamos de añadir el agua que brotaba de unos pequeños caños, discretamente colocados en las caras interiores de los veintidós pedestales de mármol de la balaustrada, caños que se pagaron al latonero Francisco Giménez y que hoy se conservan aunque están, al igual que los primitivos de la taza, inutilizados.

Si sumamos todos los puntos en que brotaba el agua, llegamos a la cifra de treinta y ocho caños, aunque hoy se reducen a ocho que salen, además, por lugares equivocados sin considerar el brutal "Chorrón" erróneamente reinterpretado, equivocadamente reubicado y que traza un eje transversal al estanque que en

35 “...una huerta que tiene... una pila de mármol con una mujer que echa agua por las tetas que viene de la noria”. ACS (Archivo de la catedral de Sevilla), Fondo Capitular, sig. ACS 09717, f. 297. 
nada se relaciona con el citado esquema rigurosamente radial de todos los demás surtidores y bastante incompatible con la sutileza de los mecanismos originales.

Las cuatro figuras de ninfas antes mencionadas debieron ocupar tal vez el lugar que hoy marcan cuatro orificios circulares que se observan sobre los hombros de la urna, entre los niños, orificios que siempre me han intrigado y que ahora podrían quedar justificados si se confirmara la hipótesis que se desprende de las noticias reunidas y puestas en relación.

Las esculturas eran de mármol blanco, las piezas de bronce fueron doradas y también el hierro recibió un tratamiento de color, ya que los balaustres forjados de las barandas fueron pintados de verde y sus nudos, dorados en frío por los pintores y batihojas Juan de Saucedo y Juan Díaz respectivamente en septiembre de $1577^{36}$.

En relación con el posible ideador de la transformación de la alberca en Estanque de Mercurio y de la reforma renacentista del resto de los jardines meridionales del Alcázar nada sabemos con seguridad. Las primeras noticias del inicio de las obras son inmediatamente posteriores a la muerte de Juan Hernández, quien en agosto de 1571 ya había fallecido, por lo que se desarrollan bajo la supervisión de Antón Sánchez Hurtado. No obstante, lo más notable de este espacio, vista su relativa simplicidad arquitectónica, son sus elementos escultóricos, de cuyo diseño y modelos tridimensionales, según la documentación antes detallada, debemos hacer máximo responsable a Diego de Pesquera. El marcado italianismo de todos ellos, no hacen sino confirmar la intuición que tuvo hace años Gómez-Moreno al lanzar la hipótesis de su formación y tal vez incluso el origen, italiano, de este personaje, de cuyas actuaciones tenemos noticias relacionadas tan solo con Granada y con Sevilla, aunque en esta última ciudad dejó una producción muy notable y digna de ser estudiada con mayor detalle.

Por todo lo comentado hasta ahora, considero de enorme interés este espacio simbólico de los jardines del Alcázar que estuvo dedicado al renovado patrón mítico de la activa, comercial y marítima Sevilla del quinientos. Y por ello estimo de gran trascendencia ciudadana la posibilidad de llevar a cabo una concienzuda restauración de este simbólico espacio, actuación que debería ser planteada en la medida de las posibilidades actuales pero siendo consciente de su enorme importancia y teniendo en consideración tanto las enormes potencialidades como

36 "a juan diaz batihoja, de oro que dio para dorar los nudos de los barahustres de las rrejas del estanque”. GESTOSO Y PÉREZ, José: Sevilla monumental..., op. cit., p. 592. "a juan diaz y juan de Saucedo, pintores, 12 ducados en rreales porque pintaron las varandas del estanque con color verde y doraron los nudos de los varahustres y las cabeças de los leonsillos que están en los pedestales”. GESTOSO Y PÉREZ, José: Sevilla monumental..., op. cit., p. 593. Ignoro a qué leoncillos se refiere este pago ya que los únicos que se ven hoy en los mismos son cuatro pequeños rostros de león, de bronce, con que se decoran las bolas de los remates de dichos elementos de mármol. 
brillante antesala de los jardines de esta ciudad palatina como también la necesidad de actuar sobre el mismo con el máximo respeto a lo que fueron sus instalaciones originales y la apariencia que quisieron darle sus creadores.

Fecha de recepción: 30 de octubre de 2018

Fecha de aceptación: 5 de febrero de 2019 


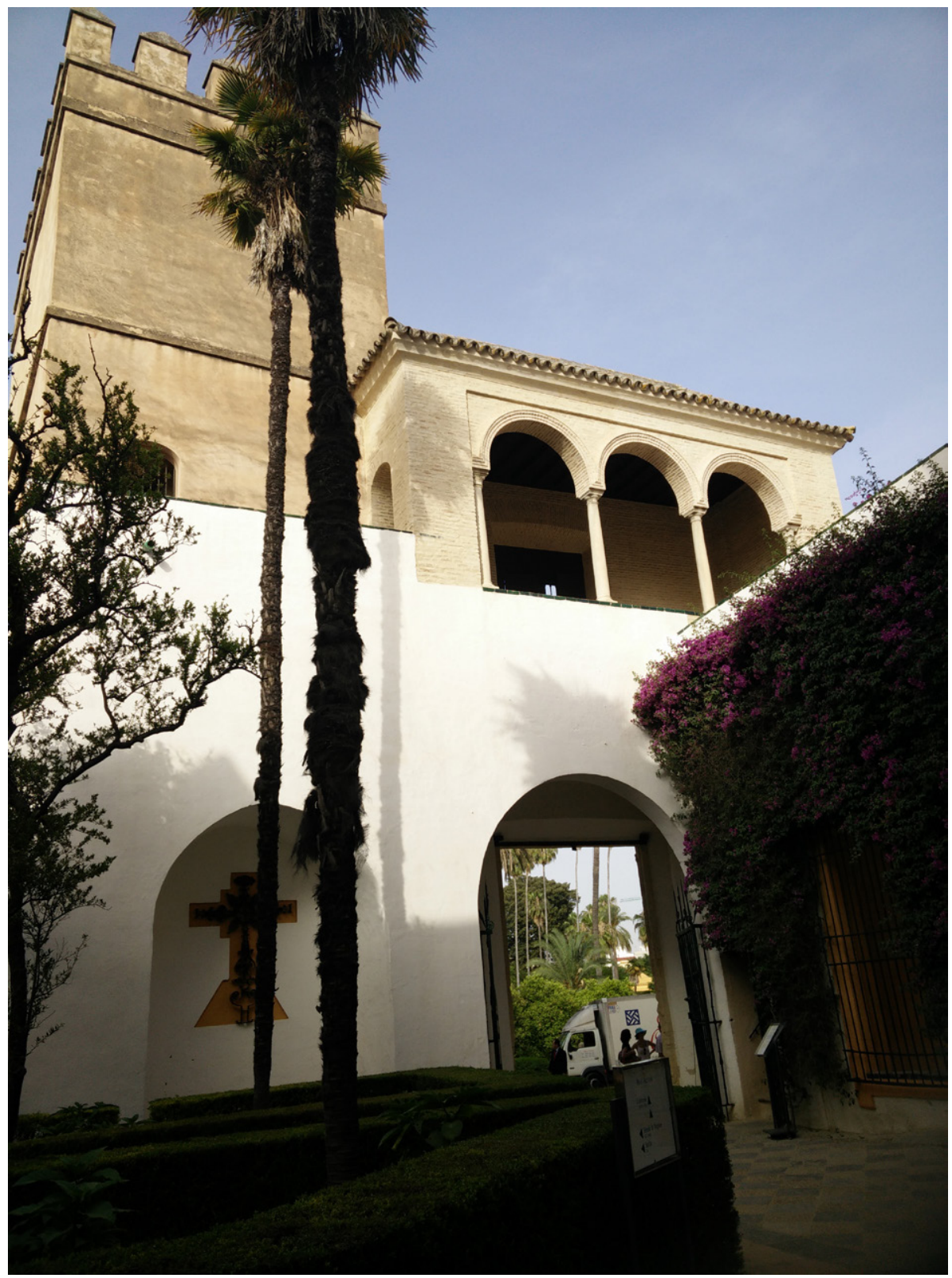

Figura 1. Jardín del Cidral (antes del Chorrón) y torre de la caja de agua. 


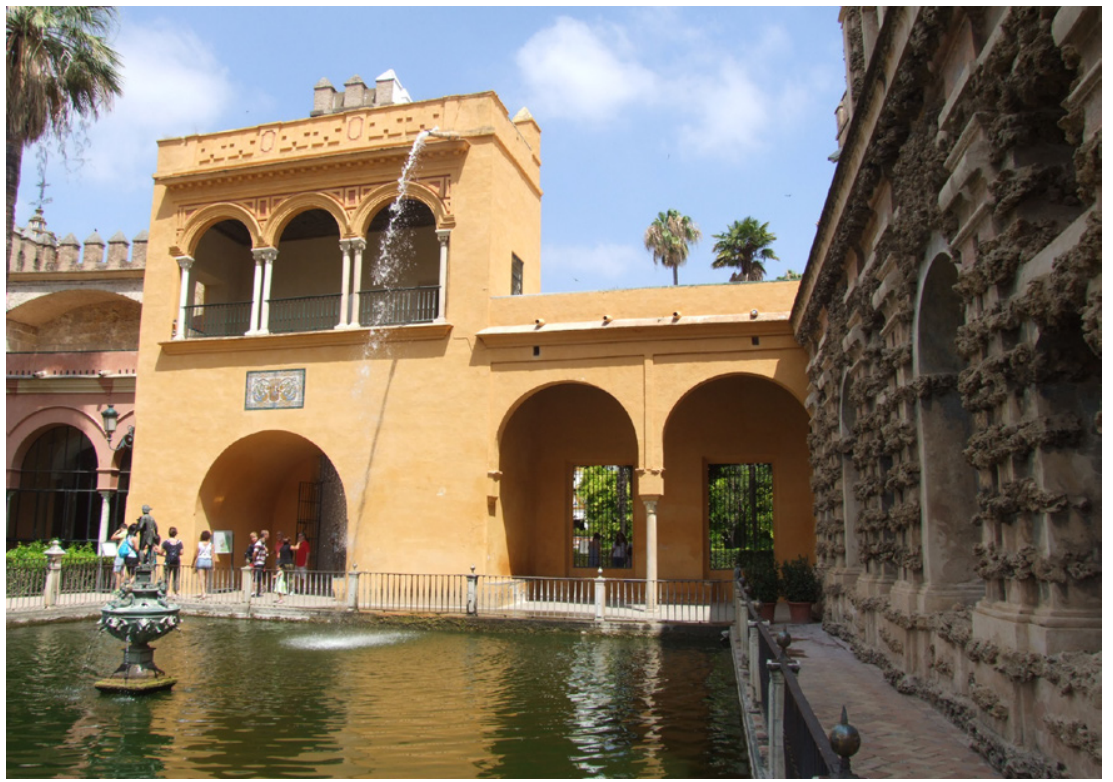

Figura 2. Paso, cenador y mirador junto al Estanque de Mercurio.

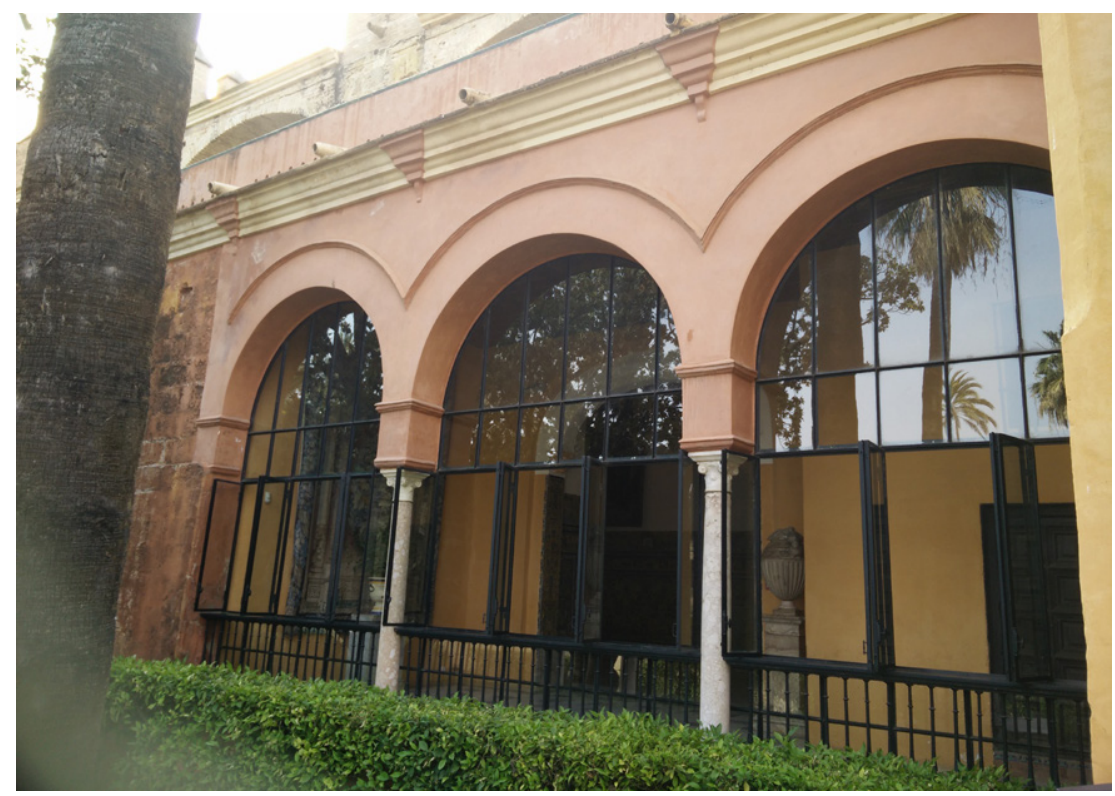

Figura 3. Galería de salida de la Sala de las Bóvedas. 


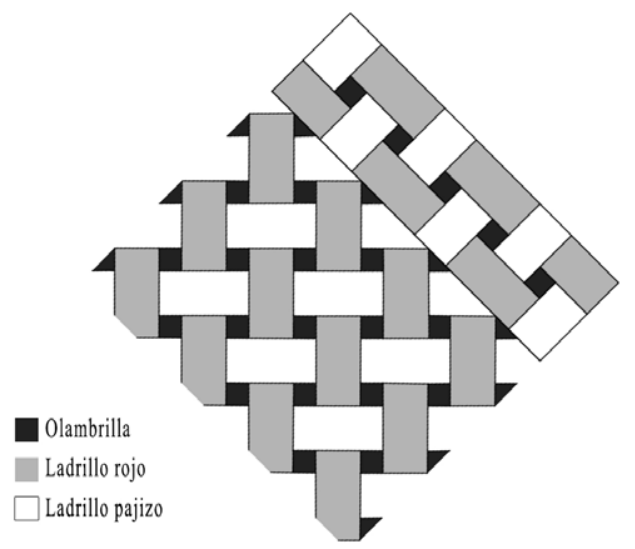

Figura 4. Esquema geométrico del pavimento. Dibujo: Pablo Peña López.

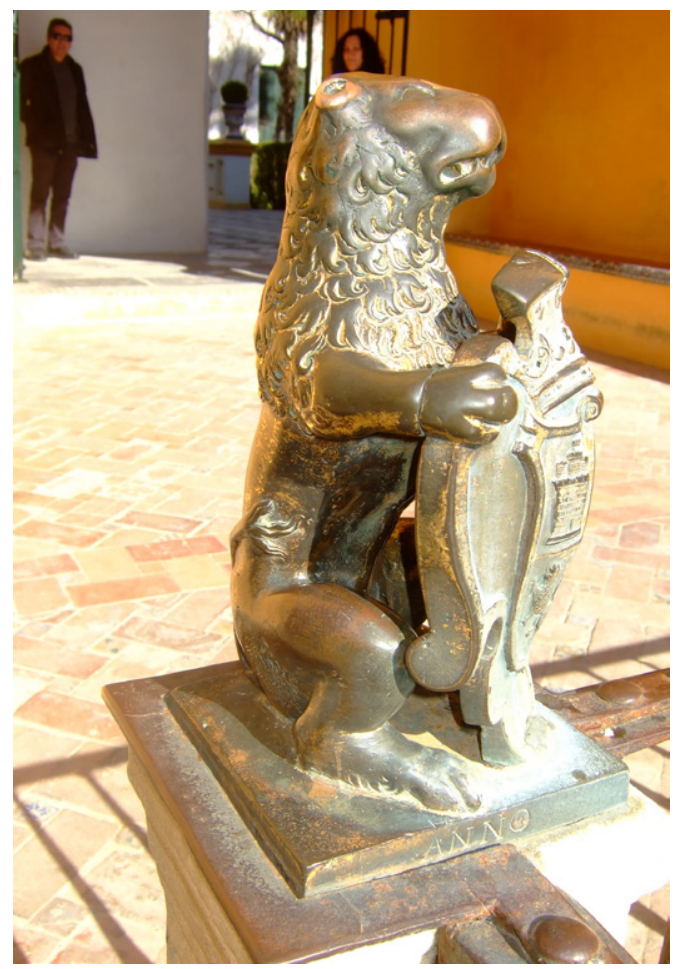

Figura 5. Remates heráldicos sobre los balaustres de las cuatro esquinas del estanque. 


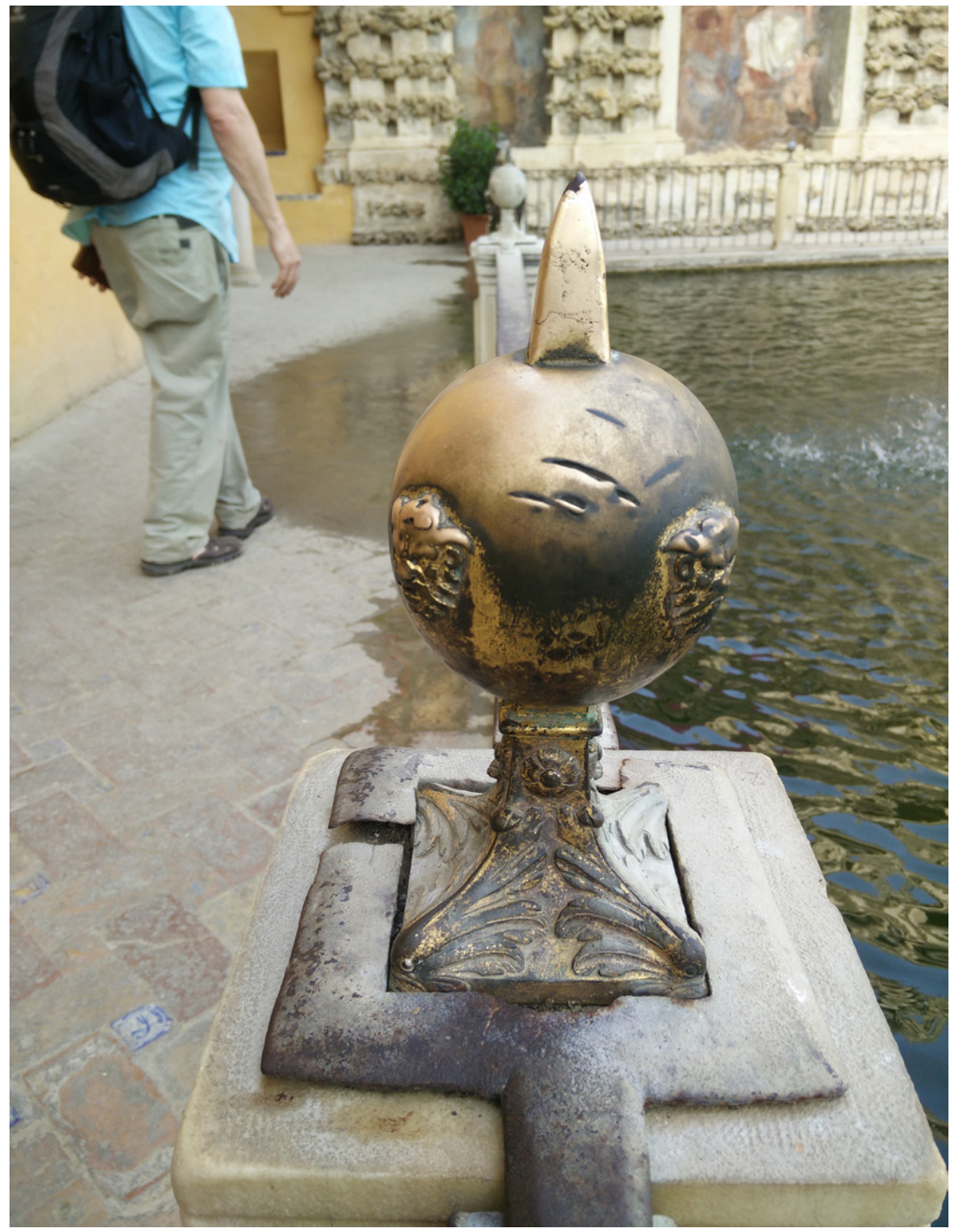

Figura 6. Remate de los balaustres de los lados rectos del estanque. 


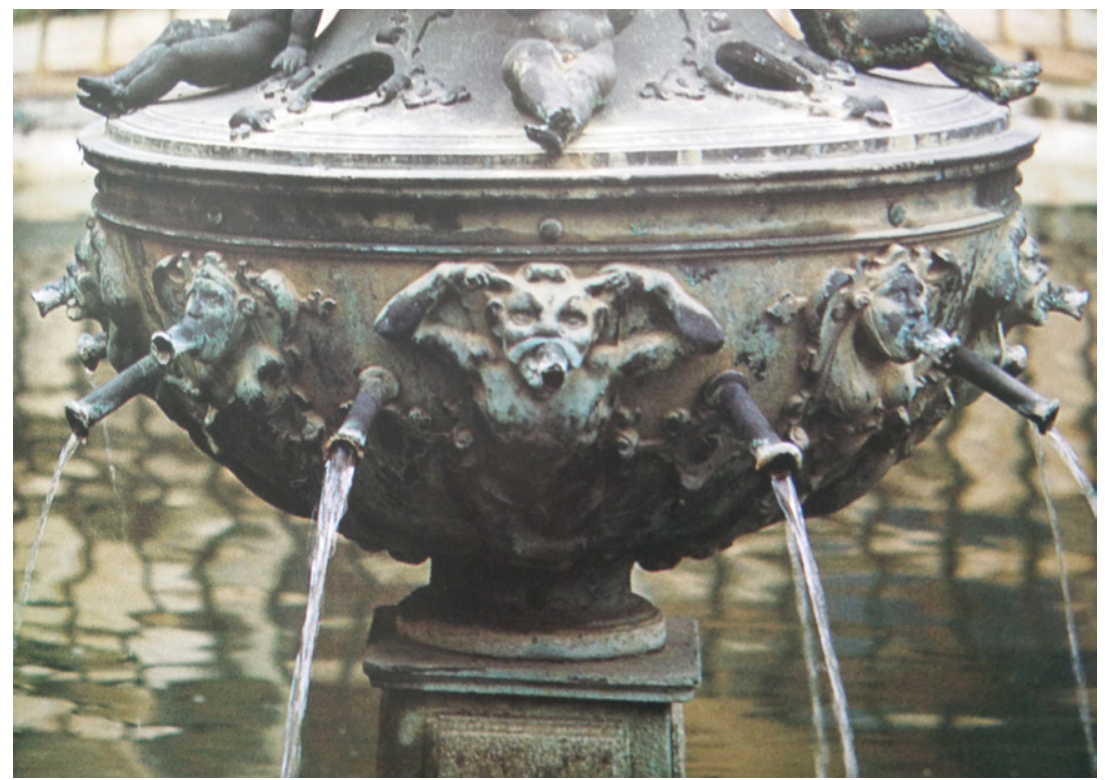

Figura 7. Urna de la fuente central del estanque. Parte inferior.

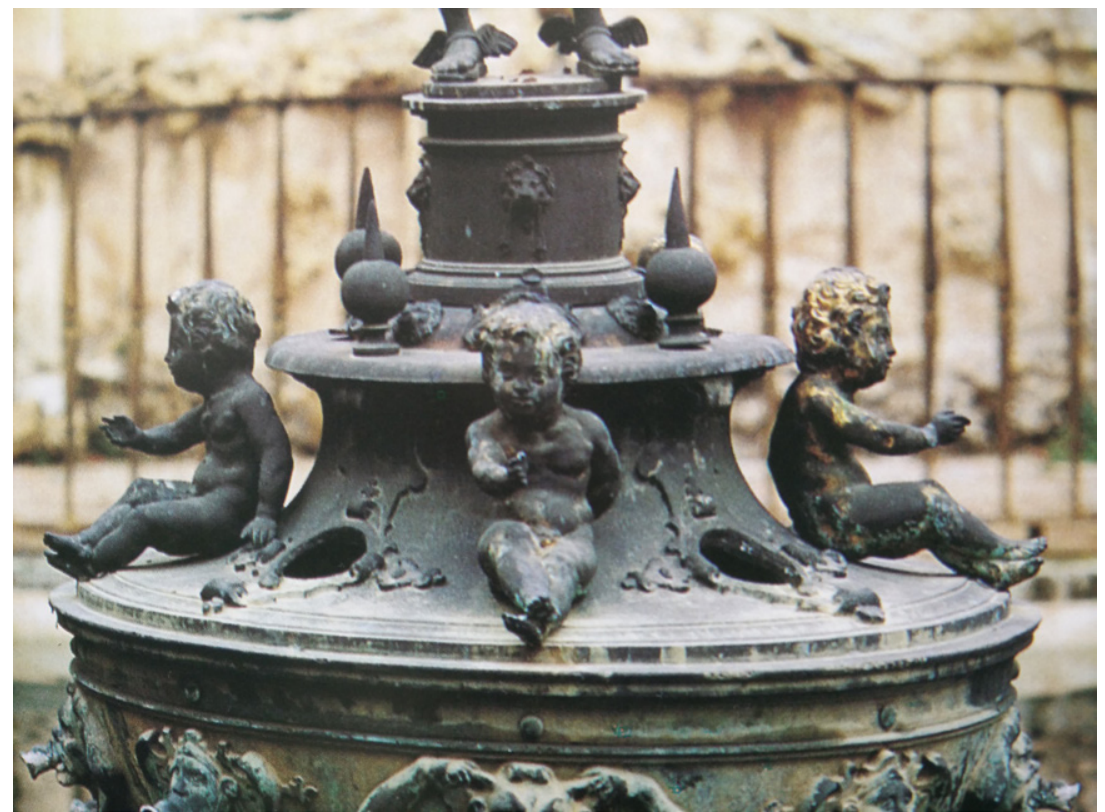

Figura 8. Urna de la fuente central del estanque. Parte superior.

LABORATORIO DE ARTE 31 (2019), pp. 209-228, ISSN 1130-5762 e-ISSN 2253-8305 - DOI http://dx.doi.org/10.12795/LA.2019.i31.12 


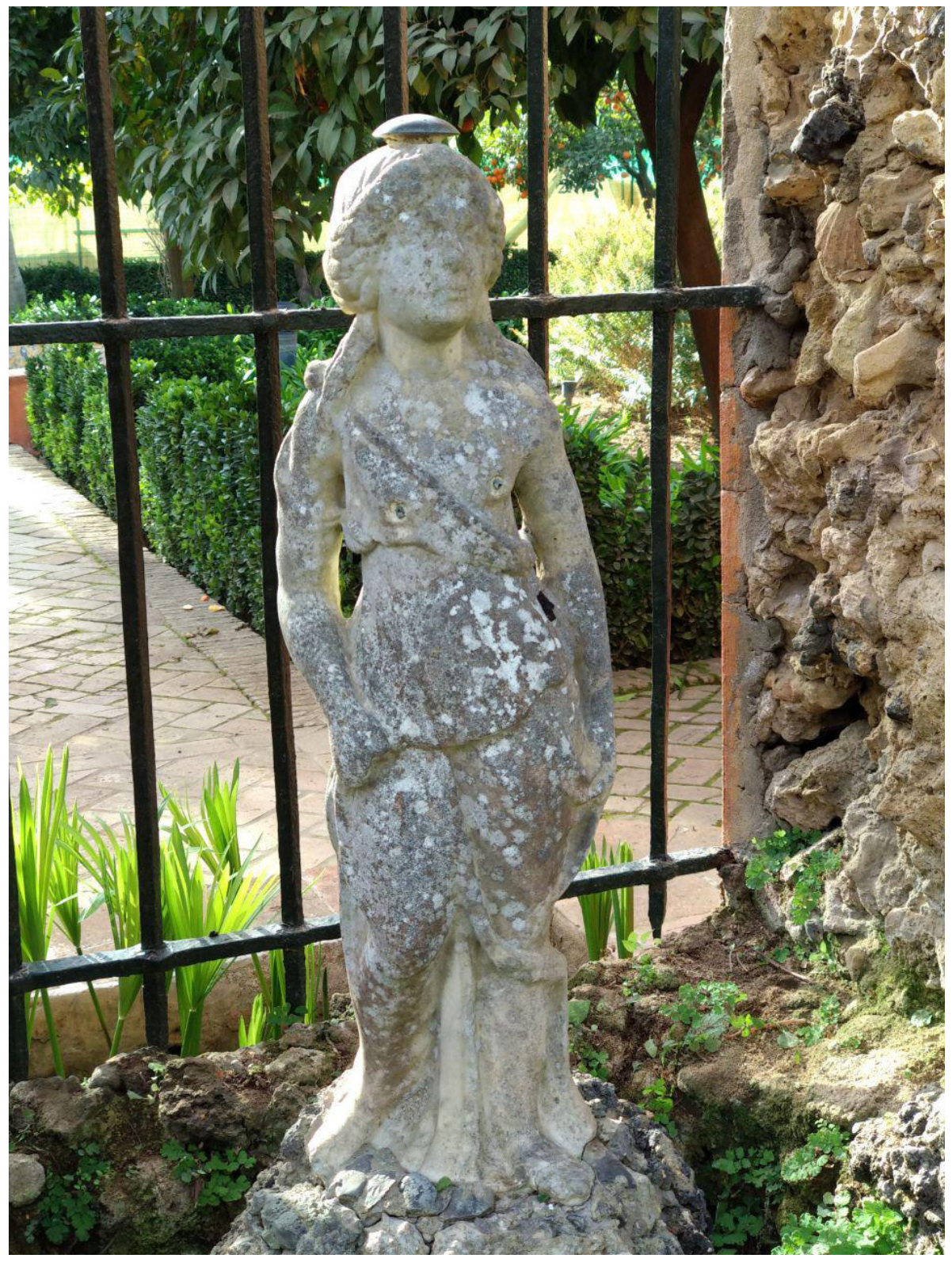

Figura 9. Ninfa hoy situada en el Jardín de las Damas.

LABORATORIO DE ARTE 31 (2019), pp. 209-228, ISSN 1130-5762

e-ISSN 2253-8305 - DOI http://dx.doi.org/10.12795/LA.2019.i31.12 